\title{
Socio-technical transitions in UK electricity: part 1 - history, actors and pathways
}

\section{Timothy J. Foxon}

Professor, SPRU - Science Policy Research Unit, University of Sussex, Brighton, Sussex, UK (Orcid:0000-0002-3095-5989)

\section{Geoffrey P. Hammond}

Professor Emeritus, Department of Mechanical Engineering,

University of Bath, Bath, UK; Institute for Sustainable Energy and

the Environment $(\cdot \bullet \mathrm{SEE})$, University of Bath, Bath, UK

(corresponding author: ensgph@bath.ac.uk) (Orcid:0000-0002-0922-8728)

\author{
Peter J. G. Pearson \\ Honorary Professor, Centre for Environmental Policy, Imperial College \\ London, London, UK; Emeritus Professor, Welsh School of Architecture, \\ Cardiff University, Cardiff, Wales, UK (Orcid:0000-0003-2447-406X)
}

A large interdisciplinary consortium of engineers, social scientists and policy analysts has developed three lowemissions, more-electric transition pathways for the UK. The approach is based on earlier work on understanding transitions, applying a multi-level perspective with landscape, regime and niche levels to the development of sociotechnical scenarios. The pathways to $\mathbf{2 0 5 0}$ focus on the power sector, including the potential for increasing the use of low-emissions electricity for heating and transport. Part 1 describes studies of historical energy and infrastructure transitions that help to understand the dynamics and timing of past transitions. The role of large-scale and smallscale actors in the electricity sector and methods used to develop the pathways are then described. In part 2 , associated technologies are evaluated to determine the choices that need to be made by UK energy policymakers and stakeholders. All three pathways are appraised in terms of their environmental performance using complementary life-cycle assessment and footprinting methods. Lessons can clearly be drawn for other industrialised nations attempting to reduce the emissions from their electricity generation systems, although local circumstances will determine country- and region-specific options.

\section{Introduction}

\subsection{Energy sector and climate change}

Human development is underpinned by energy sources of various kinds that heat, power and transport its citizens in their everyday life (Smil, 2017). However, while energy supplies and technologies underscore continued economic development, they also give rise to unwanted side effects. Arguably, the principal environmental burden emanating from the energy sector is the prospect of global warming due to an enhanced greenhouse effect induced by fossil fuel burning (Hammond, 2000; IPCC, 2013, 2019). Carbon dioxide is the principal greenhouse gas (GHG) having an atmospheric residence time of about 100 years (Hammond, 2000). This mainly arises from the combustion of fossil fuels (such as coal, natural gas and oil (petroleum)) in power stations and transport, as well as for heating in buildings and industrial processes. Changes in atmospheric concentrations of GHGs affect the energy balance of the global climate system. Human activities have led to dramatic increases since 1950 in atmospheric carbon dioxide; concentrations have risen from $330 \mathrm{ppm}$ in 1975 (IPCC, 2013) to about 408 ppm in 2018 (WMO, 2019). The most recent (2013) scientific assessment by the Intergovernmental Panel on Climate Change (IPCC) asserts that it is 'extremely likely' that humans are the dominant influence on the observed global warming since the mid-20th century. The 2015 Paris
Agreement on climate change aims to keep temperatures 'well below $2^{\circ} \mathrm{C}$ above pre-industrial levels and to pursue efforts to limit the temperature increase to $1.5^{\circ} \mathrm{C}$ above pre-industrial levels' (Ares and Hirst, 2015: p. 3). However, bottom-up national pledges received in connection with the Paris Conference for GHG mitigation efforts are expected to result in a warming of around $2 \cdot 7^{\circ} \mathrm{C}$, even if fully implemented (Ares and Hirst, 2015). Therefore, the world still faces a significant test of reducing GHG emissions further to bring global warming into line with the aspirations in the Paris Agreement. Indeed, the IPCC in its recent special report on the implications of keeping temperatures down to $1 \cdot 5^{\circ} \mathrm{C}$ (IPCC, 2019) argued that humanity has just 12 years to respond to the climate change challenge (i.e. by about 2030 rather than 2050 presently incorporated in international agreements), if it wishes to keep global warming to $1.5^{\circ} \mathrm{C}$ above pre-industrial levels. Thus, it needs to instigate appropriate actions in the very near future.

The evolution of modern industrialised society has been interwoven with discoveries of sources and uses of energy (Hammond and Pearson, 2017), especially the exploitation of fossil fuel resource stocks, the assembly of energy infrastructures, and the development of end-use technologies and practices. With its coal reserves, ports and engineering skills, Britain lay at the heart of the first industrial revolution (Allen, 2009; Wrigley, 2010). Nowadays, while energy supplies 
underpin continued economic development, this fossil fuel dependence exposes the UK to major risks: supply and resource insecurities; increasing costs of energy supply; and damage to the quality and longer-term viability of the biosphere. The British government therefore introduced a bold, legally binding aim of reducing the nation's targeted GHG emissions overall by $80 \%$ by 2050 in comparison to a 1990 baseline (DECC, 2011) in its Climate Change Act 2008. This initiative led the way globally, and subsequent pathways for achieving such levels of GHG savings are now known as 'deep decarbonisation' in much of the industrialised world (see e.g. Spencer et al., 2017). The $2^{\circ} \mathrm{C}$ global warming target agreed in the Paris Agreement (Ares and Hirst, 2015) is broadly consistent with the 2050 UK GHG emissions target. It led the British government's independent Committee on Climate Change (CCC), established under the Climate Change Act 2008, to advocate deep cuts in power sector operational emissions through the 2020s (CCC, 2015), with UK electricity generation being largely 'decarbonised' by 2030-2040. In recommending the fifth 'carbon budget' for the period 2028-2032, the CCC proposed a 57\% fall in GHG emissions overall below 1990 levels by 2032. Achieving these carbon dioxide reduction targets will require a challenging transition in Britain's systems for producing, delivering and using energy that is not only low on emissions, but also secure and affordable; thus resolving three components of the so-called energy policy 'trilemma' (Hammond and Pearson, 2017). Such GHG reductions will necessitate a rapid transition towards an energy system that delivers high-quality energy services through low-emissions technologies and processes, that are also secure and at competitive prices.

In 2018 the UK government asked the CCC to give it advice on the possible tightening of their original 2050 target in light of the Paris Agreement (Ares and Hirst, 2015). Its subsequent report advocated a new emissions target for the UK: net-zero GHGs by 2050 - that is, balancing emissions with carbon dioxide removal. The CCC argued that this target is 'achievable with known technologies, alongside improvements in people's lives, and within the expected economic cost that Parliament accepted when it legislated the existing 2050 target for an 80\% reduction from 1990' (CCC, 2019: p. 11). It also advised that the steepest reductions in GHG emissions must occur before 2030. The CCC suggested that the readily available options include: low-emissions electricity from nuclear power and renewable energy sources (bioenergy, solar photovoltaic (PV) arrays and wind turbines), which would need to quadruple by 2050; energy-efficient buildings with lowemissions heating (required throughout the UK's building stock, both new and existing structures); electric vehicles (which the $\mathrm{CCC}$ views as the only proven light vehicle option by about 2035); developing carbon dioxide capture and storage (CCS) technology; and low-emissions hydrogen (which the $\mathrm{CCC}$ regards as necessities not just options). In addition, the
CCC proposes phasing-out potent fluorinated gases, increasing tree planting, adopting measures to reduce GHG emissions on farms and stopping biodegradable waste going to landfill. Such policies should together deliver tangible GHG emissions reductions, whereas the $\mathrm{CCC}$ viewed current UK climate change policy as being insufficient to meet even the existing 2050 targets (CCC, 2019) - that is, an $80 \%$ reduction against the 1990 baseline. The Climate Change Act was subsequently amended by the UK government in June 2019 to target a reduction of all GHG emissions to net zero by 2050 (HMG, 2019).

Electricity demand in the UK as a share of overall energy consumption is likely to rise over the longer term, because it is readily controllable at the point of use and its production can be decarbonised by way of nuclear and renewable energy technologies (RET). The evolution of electricity generation systems since the time of Thomas Edison (1847-1931) has been based around the concept of employing large, centralised power stations. Thus, until recently, the bulk of electricity in Britain was generated by large thermal power plants that were connected to a high-voltage transmission grid, and then distributed to end-users by way of regional low-voltage distribution networks. Such a centralised model has delivered economies of scale and reliability, but there are significant drawbacks. It is represented schematically in Figure 1 (Hammond, 2000), where the role of the electricity network is illustrated. This power generation was resourced from some 39\% natural gas, $33 \%$ RET (wind turbines, solar PV cells, hydropower and bioenergy), $18 \%$ nuclear power and $5 \%$ coal in 2018 , the most

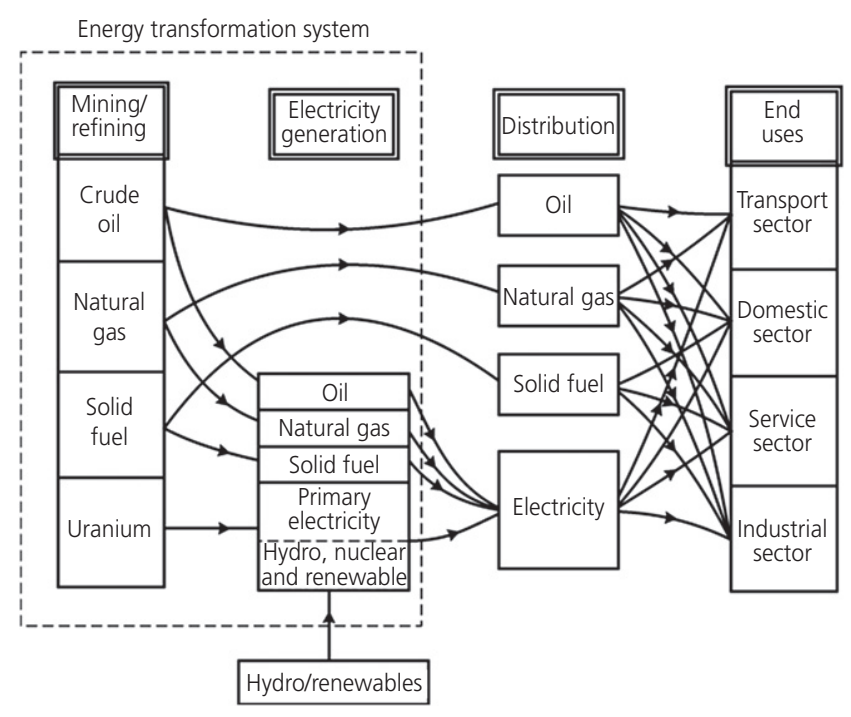

Figure 1. Simplified representation of the UK energy system (source: Hammond (2000)) 
recent full year data available at the time of writing in the annual Digest of United Kingdom Energy Statistics (Dukes) (BEIS, 2019). Consequently, the UK electricity supply industry (ESI) is still nearly $50 \%$ dependent on primary fossil fuels that is, natural gas and coal. Heat is lost or energy 'wasted' at each stage of the system, from extraction of primary resources to end-uses that meet demand (Hammond, 2000). Much of the electricity grid was constructed in the 1950s and 1960s. It is therefore heavily reinforced in former coal-mining areas, and is nearing the end of its design life. It restricts the power flow from Scotland to England $\left(2 \cdot 2 \mathrm{GW}_{\mathrm{e}}\right)$, and by way of the interconnectors (in the form of high-voltage undersea cables) to France, Northern Ireland and the Netherlands. The grid will therefore require not only renewal, but also reconfiguration of both hardware and software to accommodate the introduction of greater levels of distributed generation in the future within the home or on a community scale.

\subsection{Transitions approach}

Dutch researchers have pioneered research on transitions in socio-technical systems, which has expanded, diversified and deepened during the last decade, under the broad heading of 'sustainability transitions' (Kohler et al., 2019; Markard et al., 2012). It has influenced their national policy on promoting energy system transitions (Kemp et al., 2007; Kern and Smith, 2008; MEA, 2015; Verbong and Geels, 2010), and stimulated historical case studies (Kemp and van Lente, 2011), including applications to the Dutch electricity system (Kwakkel and Yücel, 2014; Verbong and Geels, 2007). Other analyses have examined transitions from sailing ships to steam ships (Geels, 2002); from horse-drawn to automobile transport systems (Geels, 2005); from cesspools to sewer systems (Geels, 2006); and biogas development in Denmark (Geels and Raven, 2006). It has been used to examine the dynamic interaction of technological and social factors at different levels (Elzen et al., 2004; Geels, 2005), and has generated significant international policy and research interest (Chilvers et al., 2017; Foxon, 2013; Foxon et al., 2010; Geels, 2002; Hammond and Pearson, 2013, 2017; Kemp, 1994; Markard et al., 2012; Voß et al., 2009). This analytical approach is typically coupled with a multi-level perspective (MLP) for analysing socio-technical transitions, based on co-development at and between three levels (Geels, 2002; Kemp, 1994): niche innovations, socio-technical regimes and macro-landscape pressures (see e.g. Figure 2 (Foxon et al., 2010)). The landscape represents the broader political, social and cultural values and institutions that form the deep structural relationships of a society and only change slowly (Chilvers et al., 2017). The socio-technical regime reflects the prevailing set of routines or practices used by 'actors': those involved with the design, implementation, operation and use of a particular technological system or network (see e.g. de Bruijn and Herder, 2009; Rip and Kemp, 1998). While the existing regime is thought of as generating incremental innovation, radical innovations are generated in niches (Geels, 2002; Kemp, 1994). The latter are 'protected' spaces that are at least partially insulated from normal market selection in the regime. Niches provide places for learning processes to occur, and space to build up the social networks that support innovations, such as supply chains and user-producer relationships.

The transitions approach has been used as a basis for developing 'transition management'. This is a process of governance seeking to steer or modulate the dynamics of transitions through interactive, iterative processes between networks of stakeholders. It involves creating shared visions and goals, mobilising change through transition experiments, as well as the evaluation of the relative success of these experiments (Kemp and Rotmans, 2005; Loorbach, 2007; Loorbach et al., 2015). Transition management is thus a form of participatory policy making based on complex systems thinking. However, the transitions theory or socio-technical approach is not without its critics (Barton et al., 2018; Geels, 2010; 2011, 2012, Geels and Schot, 2007). Although Shove and Walker (2007) recognised the value of 'sustainable transitions management' for stimulating change towards predefined beneficial goals, they argued that analyses based on the MLP typically have an over-simplified view of the social realm, being rooted in innovation studies' (see e.g. Smith et al., 2010). In a response, Rotmans and Kemp (2008) noted that it is an approach that has been used in the Netherlands in particular (see also Kemp et al., 2007; Kern and Smith, 2008; Kwakkel and Yücel, 2014; MEA, 2015; Verbong and Geels, 2007, 2010) to aid the achievement of better futures. Transitions management helps secure incremental system improvements and innovations within the planning framework; often in the face of complexity and uncertainty. Indeed, Grubler (2012) drew on real-world historical energy transitions to highlight the long duration of transitions (many decades) and their slow rates of change, the importance of energy end-uses as drivers of change, and the distinctive patterns needed for the scale-up of technological solutions. However, even Grubler (2012) provided cautionary tales. He suggested that low carbon dioxide ('low-carbon') transitions require persistence and continuity of policies, their alignment (e.g. regarding fossil fuel subsidies), and balanced innovation portfolios (e.g. public sector R\&D investment and niche market incentives). Geels and Schot (2007) developed a more detailed typology of transition pathways, focused on refinements to the MLP, in response to critiques and insights in the academic literature (Meadowcroft, 2009; Rotmans and Kemp, 2008; Shove and Walker, 2007; Smith, 2009) that were followed-up by Geels $(2010,2011,2019)$. Although many successful transition paths reflect a sequence of events (Geels and Schot, 2007), they are not automatic or deterministic. Many of the pathways may not, in reality, turn out to have a pure format (Geels, 2010, 2011; Geels and Schot, 2007), and shifts 


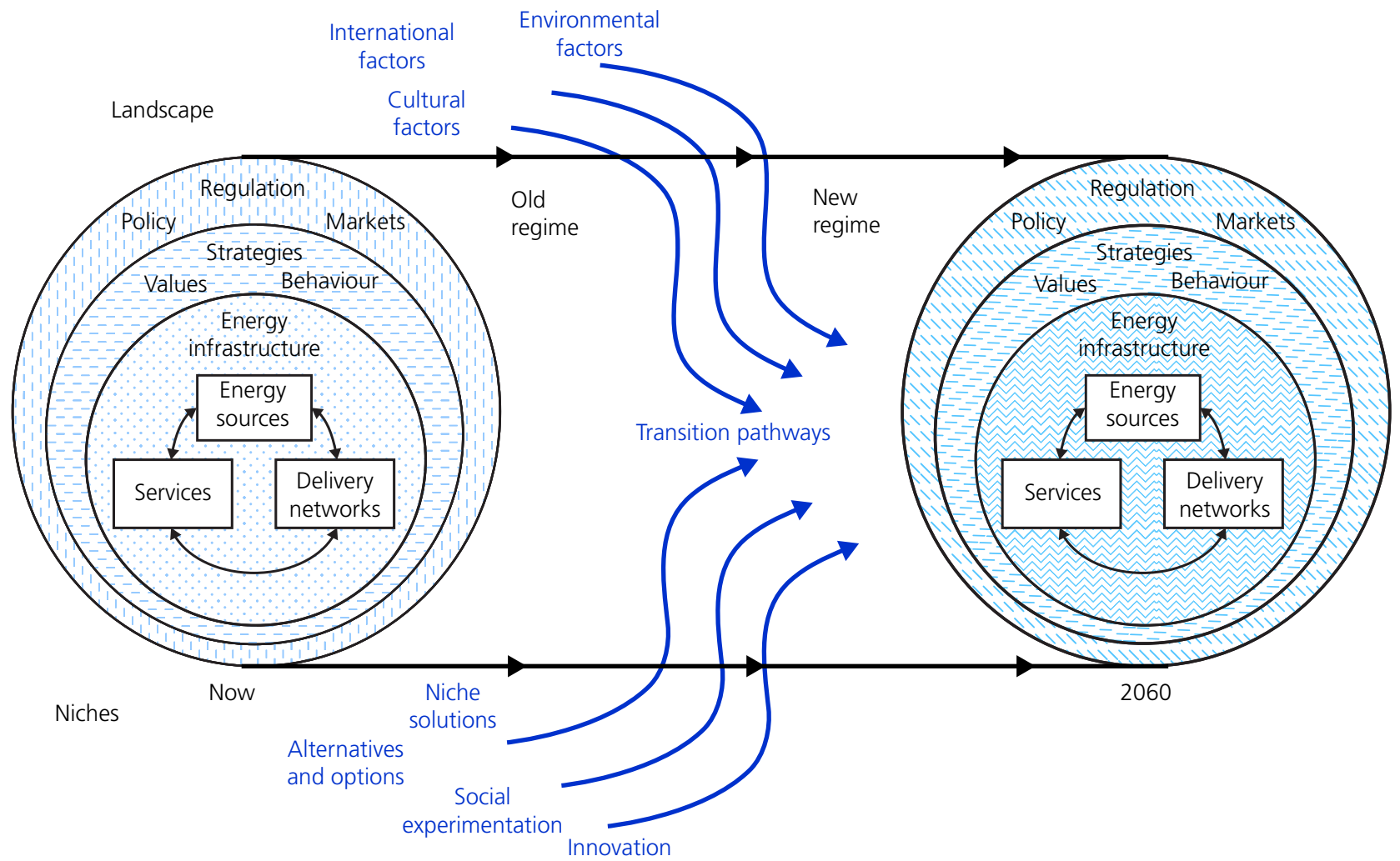

Figure 2. Possible transition pathways and the factors that influence them (source: The Transition Pathways Consortium; Foxon et al. (2010))

between them can result in those exhibiting mixed characteristics (Geels et al., 2016).

An initial theoretical analysis of past and possible future 'decarbonisation' pathways for the UK (Shackley and Green, 2005) showed the potential for the application of the transitions approach in Britain. Shackley and Green (2005) identified a number of key socio-technical factors that would influence future pathways in terms of policy drivers for change A number of studies have applied the MLP for a comparative analysis of low-carbon electricity transitions in, for example, Germany, the Netherlands and the UK (Geels et al., 2016; Laes et al., 2014). These countries were selected as exemplars of the deployment of RET (Laes et al., 2014), of a transition management framework (Kemp et al., 2007; Kern and Smith, 2008; MEA, 2005; Verbong and Geels, 2007) and of legislative commitment to climate change mitigation (Climate Change Act 2008), respectively. They identified best governance practices, for example, creating communities of interest, target setting to link long-term strategies with shorter-term (energy or carbon) budgets and the adoption of policy incentives. Geels et al. (2016) built on the revised typology of Geels and
Schot (2007) in their comparison of Germany and the UK electricity transitions. They observed that the dominant transition pathway in Germany was based largely on technological substitution enacted by new entrants who have led the deployment of small-scale RET (Laes et al., 2014). In contrast, incumbent actors (such as what, until recently, was known as the 'big six' electricity utilities) led the deployment of largescale RET in the UK; mainly onshore, and more recently offshore, wind farms. However, the British policy incentives for RET have been significantly weakened over the last decade (Barton et al., 2018), although Geels et al. (2016) believe it is likely that the UK will still meet its current renewable electricity target of $30 \%$ by the end of 2020 under the European Union agreement. Market conditions have led to a share of electricity generation from RET being 33\% in 2018, according to Dukes (BEIS, 2019). Likewise, the take-up of new nuclear power stations and CCS facilities coupled to fossil-fuelled power stations and industrial process plants have been significantly delayed in comparison with what was initially envisaged in the early 2010s (Cooper and Hammond, 2018). The delay by the UK government in publishing an update to its original Carbon Plan (DECC, 2011) may reflect the challenges in 
ensuring that the UK remains on track for further emissions reductions in the late 2020s and early 2030s (Barton et al., 2018). This plan subsequently became The Clean Growth Strategy (HMG, 2017), and links a low-carbon transition to an updated national industrial strategy (Busch et al., 2018; Cooper and Hammond, 2018).

\subsection{Issues considered}

A large interdisciplinary consortium of engineers, social scientists and policy analysts has developed three low-emissions transition pathways for a more electric future in the UK out to 2050: termed 'market rules' (MR), 'central co-ordination' (CC) and 'thousand flowers' (TF). (This large consortium of nine university partners was originally funded by way of the strategic partnership between E.on UK (the electricity generator) and the UK Engineering and Physical Sciences Research Council (EPSRC) to study the role of electricity within the context of 'Transition Pathways to a Low Carbon Economy' (2008-2012), and then renewed with funding solely from the EPSRC under the title 'Realising Transition Pathways: Whole Systems Analysis for a UK More Electric Low Carbon Energy Future' (RTP) (2012-2016).) This research study examined the most recent version 2.1 (v2.1) of the pathway narratives (Barton et al., 2018; Chilvers et al., 2017; Hammond and Pearson, 2017): driven by the market (MR), central government intervention (CC) and civil society (TF) (e.g. local communities and non-governmental organisations (NGOs)) initiatives: see Table 1. This emphasis on 'governance' as a prime mover of market development is a novel feature in terms of energy futures research in Britain (Chilvers et al., 2017; Foxon et al., 2010; Hammond and Pearson, 2013). (The TF pathway's name was loosely inspired by the late Chairman Mao Zedong's 1957 invitation to Communist Party cadres in China to criticise the political system then in place within the country: 'Let a hundred flowers blossom' (often misquoted as the bottom-up injunction to 'Let a thousand flowers bloom'
(Chilvers et al., 2017)).) This transition pathways research has focused on the choices and actions needed to get there from here, and on the analysis of the pathways' technical, socioeconomic and environmental implications. It built on an approach based on earlier work on understanding transitions, as discussed in the previous section. These 'socio-technical scenarios' or transition pathways focus on power generation, including the potential for increasing the use of low-carbon electricity for heating and transport. The extent to which choices need to be made by UK energy policymakers and stakeholders between the large-scale and small-scale actors, pathways and associated technologies are discussed below.

The current research programme sought to understand and contribute to potential future transitions of UK energy systems and to enhance policy thinking and decision making. Here (in part 1), studies of historical energy and infrastructure transitions - which inform how the broad, long-term sweep of change that arises out of interactions between actors or actor networks, institutions and infrastructures - have helped understand the dynamics and timing of transitions (Chilvers et al., 2017; Pearson, 2018). MLP - encompassing, as noted above, macro-landscape pressures, socio-technical regimes and niche innovations - has been used as the basis for developing the socio-technical scenarios (as depicted in Figure 2), which can be employed to explore the potential future development of socio-technical systems through interactions between ongoing processes at the three levels (Elzen et al., 2004; Foxon, 2013; Hammond and Pearson, 2013, 2017).

In part 2, all three pathways (MR, CC and TF) are evaluated in terms of their environmental performance using complementary life-cycle assessment (LCA) and footprinting methods. The energy analysis and environmental LCAs reported by Hammond et al. (2013) and Hammond and O'Grady (2014, 2017a, 2017b) evaluated v1.1 and v2.1 of the

Table 1. Key characteristics of the UK transition pathways

\begin{tabular}{|c|c|c|c|}
\hline Pathway designation & MR & $\mathrm{CC}$ & TF \\
\hline Governance logic & Market & Government & Civil society \\
\hline Critical technologies & $\begin{array}{l}\text { Fossil fuel (coal and gas) CCS; } \\
\text { nuclear power; offshore wind. }\end{array}$ & $\begin{array}{l}\text { Fossil fuel (coal and gas) CCS; nuclear } \\
\text { power; offshore wind. }\end{array}$ & $\begin{array}{l}\text { Solar PV arrays; onshore and offshore } \\
\text { wind; renewable CHP. }\end{array}$ \\
\hline Important trends & $\begin{array}{l}\text { Limited interference in market } \\
\text { arrangements; high-level policy } \\
\text { targets and high carbon price. }\end{array}$ & $\begin{array}{l}\text { Central government commission } \\
\text { branches of low-carbon generation } \\
\text { from big companies to reduce risk } \\
\text { of low-carbon investment. }\end{array}$ & $\begin{array}{l}\text { Local, bottom-up diverse solutions led } \\
\text { by local communities and NGOs, } \\
\text { greater community ownership and } \\
\text { more engagement of end-user. }\end{array}$ \\
\hline Electricity demand & $\begin{array}{l}\text { Increase demand for heating and } \\
\text { transport. Overall demand in } \\
2050 \text { ( } 512 \text { TWh) is much } \\
\text { greater than today. }\end{array}$ & $\begin{array}{l}\text { Increase demand for heating and } \\
\text { transport, but reduced through } \\
\text { energy efficiency. Overall demand in } \\
2050 \text { ( } 410 \text { TWh) is slightly higher } \\
\text { than today. }\end{array}$ & $\begin{array}{l}\text { Overall demand in } 2050 \text { ( } 310 \text { TWh) is } \\
\text { lower than today. Higher rate of } \\
\text { energy efficiency improvements and } \\
\text { more aware consumers. }\end{array}$ \\
\hline
\end{tabular}

Note: source: Chilvers et al. (2017); adapted from Foxon (2013). CHP, combined heat and power. 
pathways, respectively. Environmental footprint analysis (EFA) is also employed to estimate the environmental and resource burdens associated with UK power generation based on historic data and the three transition pathways (Hammond et al., 2019).

\section{The UK energy sector - role of actors}

The 'governance' of energy systems involves choices made by different actors within the sector, such as national and local policymakers, large firms and new entrants, financial investors and end-users, that give rise to changes to the system (Smith, 2009). These actors have a range of individual and social goals, including the supply, provision and use of energy services at reasonable costs, maintaining security of supply, and contributing to wider social and environmental aims, which may often be conflicting - but are sometimes harmonious - in any particular decision process. Institutional arrangements frame the way that these conflicts are resolved, or synergies reinforced, and so strongly influence the governance of energy systems. Furthermore, they interact with present and expected future changes in technologies, as such changes create new opportunities and challenge existing arrangements (having new information about the risks of climate change), and with new institutional arrangements and governance processes that create incentives for development of, and investment in, particular technologies and their uses.

The current UK energy regime for meeting lighting, heating and power-related services may be characterised as a centralised system (see Dukes (BEIS, 2019)). Electricity is generated centrally, largely from fossil fuels (now mainly natural gas), nuclear power and a growing set of renewable resources (i.e. RET). Natural gas is extracted from the North Sea or imported by way of pipelines or as liquefied natural gas (LNG). It is delivered to homes and businesses through the transmission and distribution networks, before being used to provide end-use services, together with distributed energy resources (DER) that is, small-scale units of local generation connected to the grid at the distribution level - and the buildings infrastructure. Natural gas is also delivered through a transmission and distribution network, and used to provide heating and cooking services with the aid of end-use technologies and the buildings infrastructure. The markets for the provision of electricity and gas were liberalised in the late 1980s and 1990s to facilitate competition between electricity generators, and between companies supplying electricity and gas to homes and businesses, overseen by a regulator Ofgem, with the aim of reducing the costs of generating and supplying energy to users. The strategic importance of energy for enabling well-being and economic activity means that the system is the subject of intense policy activity, focused on ensuring continuing, affordable supplies, and meeting other social and environmental objectives, including climate change and global heating.
Key processes at the landscape level (see Figure 2) influencing and 'driving' the energy regime include: (a) public awareness of climate change and willingness to accept and undertake changes in response; $(b)$ government commitments to meet national and international targets for emissions reductions and promotion of low-carbon energy sources; $(c)$ ideological commitments to liberalised energy markets; $(d)$ concerns over security of primary energy supplies (including external factors leading to high oil and gas prices); and (e) factors which could lead to physical disruption of external supplies (war, terrorism, foreign governments limiting supply, etc.). The dominant processes are focused on the energy policy trilemma: government commitment to national and international targets for moving to a low-carbon energy system, concerns over security of supply, and issues of affordability, competitiveness and fuel poverty. The UK has signed up to, and was one of the drivers of, the European energy and climate policy back in 2007. This set targets for 2020 of a $20 \%$ reduction in European carbon dioxide emissions, a $20 \%$ increase in energy efficiency and $20 \%$ of final energy to come from RET. Such landscape-level commitments contained in both national and European energy and climate policy targets that need to be translated into direct pressures on the energy regime through enhanced policies and measures.

Another driver of UK energy policy at the landscape level is concerns over security of primary energy supplies. A variety of factors anticipated between now and 2030 have led to a perceived generation 'gap' and concerns about availability of primary energy sources to enable this supply deficit to be filled, while achieving carbon-reduction targets. This policy arena has been strongly driven by lobbying from actors, including large incumbent utility companies within the existing regime seeking to maintain the current centralised generation system and their role in it. An interesting potential institutional innovation was a proposal to sell energy services rather than units of energy, which was encouraged under the British government's Carbon Emission Reduction Target (CERT) scheme that operated over 2008-2013. This required energy suppliers to stimulate take-up of low-carbon and energyefficient measures by their customers. This type of scheme could potentially lead over the long term to significant changes in business strategies for large industry players, particularly if they face challenges from new entrepreneurial energy service companies. How these different pressures affect business strategies depends partly on the way in which firms perceive the various commercial risks within the energy system. A survey of a range of stakeholders identified the major risks associated with a rapidly changing UK electricity sector as being: reliance on insecure sources of primary fuels for electricity generation; lack of investment in new infrastructure; decommissioning of nuclear plant leading to reduced capacity; severe weather conditions arising from climate 
change; and maintenance of capacity margins (Hammond and Waldron, 2008).

The potential exists for a move away from largely centralised electricity systems towards more decentralised ones (Barton et al., 2018). While many different alternatives exist within each of these routes, they are significantly different from each other, particularly in terms of infrastructures, institutions and patterns of behaviour. These can be characterised as follows.

(a) Centralised generation systems. Concerns over security of supply, and doubts about the potential to scale-up local decentralised technologies, may reinforce strategies of large energy companies to maintain portfolios of large-scale technologies, including natural gas and nuclear power plants. Hence, investment focuses on these technologies, alongside scale-up of offshore wind, and reinforcement and enhancement of existing transmission infrastructure. The way that targets for emissions reductions and renewable energy sourcing are institutionalised could allow investment by UK companies overseas to count towards UK targets, and so UK domestic targets would become less stringent, delaying early action on decentralised options, and reducing the overall pace of change. This investment in centralised technologies, and associated infrastructure, might crowd out the potential for large investments in decentralised options.

(b) Decentralised or distributed generation systems. Technical, social and economic concerns relating to the main centralised options, including CCS, nuclear power and offshore wind, may lead to greater, renewed interest in decentralised options. Strong local leadership and sharing of knowledge between entrepreneurial local authorities could be reinforced by advocacy coalitions of small-scale actors: technology developers, installers and new energy service companies (ESCos) promoting decentralised generation (DG). Infrastructure investment might focus on enhancing capacity of distribution networks to actively manage two-way power flows and on investment in the built infrastructure to utilise DER and capture natural energy flows - for example, through passive solar design and natural ventilation.

\section{Past, present and prospective energy transitions}

Studies of historical energy and infrastructure transitions have helped understand the dynamics and timing of transitions (see e.g. Pearson, 2018; Sovacool and Geels, 2016; Wilson and Grubler, 2011). Policymakers tend to have little institutional memory of what has worked or has not worked in terms of energy sector interventions, because job changes are used to enable UK civil servants to gain experience and avoid accumulating positional or departmental loyalty, and because ministers often serve for short periods (Chilvers et al., 2017): from 2008 to 2015 of the four UK Secretaries of State for Energy and Climate Change, one served for less than 2 years and another for just over 1 year. Historical analyses/stories of past transitions therefore help them (and other stakeholders) to understand how and why transitions have previously succeeded or failed. They also indicate how long they can take to implement and the reasons why. However, Pearson (2018) recently noted the growing policy focus on 'low-carbon transitions', which address the threat of climate change by seeking transitions away from GHG-emitting fossil fuels, towards lowcarbon renewable and/or nuclear power. He explored three areas in which further historical analysis could be especially valuable: $(i)$ research into the duration and speed of past energy system transitions and the insights to be gained from their analysis; (ii) path dependence, lock-in and the strategies, responses and destabilisation of incumbent energy actors and institutions; and (iii) theoretical and empirical approaches to 'sustainability transitions' and innovation. While most attention has been paid to transition successes, belated attention is now being paid to transition failures and resistance to change by incumbent firms, as well as their fuels, technologies and institutions (Chilvers et al., 2017). Historical case studies also help illustrate the possibility of radical or rapid transformation; and raise questions about the received wisdom regarding past successes/failures of socio-technical transitions, policies and technologies. The value of historical case studies as analogues lies not in their perfect fit with modern technologies or circumstances (which is unlikely), but in being similar in one or more aspects and yielding insights from the analysis of such similarities and differences.

The historical studies have shown that rapid change is possible, but not necessarily frequent. It may require both recognition of the need to change, openness to experiment and a high degree of co-ordination (e.g. the natural gas transition). These studies illustrate how co-constructed are the material or physical aspects with the social, political and institutional aspects. For example, the successful 1966-1977 conversion from town gas to North Sea natural gas (under the management of the nationalised British Gas Corporation) required both technical changes, including building the national gas grid and installing new burners in millions of gas appliances, along with major institutional reorganisation, new workforce training and political support (Arapostathis et al., 2014, 2019). Pearson and Arapostathis (2017) explored seven transitions in the UK gas industry since its inception in 1805. This paper and that of Arapostathis et al. (2019), which focused on the conversion of gas-using appliances, question whether the current UK gas industry is as well situated to adjust to the low-carbon transition, particularly the heat transition, as the industry of 
the 1960s was to the transition from town gas to natural gas. They also identify and explore the challenges faced by government in helping to steer this transition.

The subsequent privatisation and liberalisation of the gas market after 1987 led to major structural change and a system regulated by Ofgem, with a Uniform Network Code (UNC) overseen by the Joint Office of Gas Transporters. Vertical integration was aided by new control and communication technologies, together with internationalisation by way of gas interconnectors. That reduced uncertainties, but increased the system's complexity. This case study (Arapostathis et al., 2014) provided an analogue for the challenges of integrating large, infrastructural technical systems for a sustainability transition. It is inscribed within the MLP approach yet concentrates on system integration as a complex and uncertain socio-technical process. Consequently, it indicates how quite dramatic changes in the UK natural gas structure are mirrored in regime formation (see again Figure 2).

Historical studies of two alternatives to petrol in the inter-war period (Johnson et al., 2016) show how and why emerging technological substitutes can founder and potential transitions fail in times of economic instability, shifting governance and competition between incumbents and newcomers. This study compared transition experiences and branching points (i.e. points at which key regime actors felt the need to take decisions to stay on or depart from an existing pathway) of emerging alternative liquid fuels in Britain during previous recession and growth periods between the First and Second World Wars - that is, 1918-1938. The case studies focused on alcohol fuel produced by the Distillers Company Ltd. (DCL) for power generation and petrol-from-coal produced by Imperial Chemical Industries (ICI). Both fuels received government support during a time of rapid growth in the motor industry, fluctuating economic conditions and fears of absolute oil shortages. They represent examples of failed attempts at path creation and transition. Nevertheless, the studies identified the importance of network infrastructure, ownership of this infrastructure and the impact of energy security on prevailing governance framings or 'logics'. Thus, Johnson et al. (2016) observed that when energy is seen as 'insecure', it tends to be framed as a social service (or article of warlike material) rather than a commodity, with growing political legitimacy of policy interventions. They found that crude oil market instability, support for a declining coal industry, and militaristic needs all motivated the search for these alternative liquid fuels in the inter-war period. Governance of fuel distribution had significant effects on the economic feasibility of both fuels and their ability to penetrate a market dominated by the oil industry incumbents. Changing characteristics of energy security influenced the framing of energy and shifts in government support for alternative transport fuels. Lack of state regulation of incumbent oil company cartels and access to fuel distribution infrastructure impeded emergence of these new fuels. This analysis of failed attempts at path creation (Johnson et al., 2016) can therefore usefully inform understanding of current energy governance and low-carbon transitions.

There is relatively little historical work on demand reduction. However, the recent study of the Electricity Development Association (EDA) and domestic electric heating in early post-war Britain (Carlsson-Hyslop, 2016; Chilvers et al., 2017) suggests that the electricity industry's attempts at persuading consumers to reduce demand illustrate some of the challenges facing demand reduction today. The EDA, originally established as a public relations arm of the UK electricity industry, tried simultaneously to reduce undesirable peak demand while encouraging increased demand more generally. In the late 1940s it recommended that electric fires should not be used to meet peak demand. However, in the 1950s and 1960s, the EDA, focusing on the growing market for central space heating, concentrated on promoting off-peak heating appliances. It first sought to do this in the UK by way of underfloor heating, and then block storage heaters typically composed of clay bricks or other ceramic material. The study analysed the way in which the then London County Council (LCC) and its tenants adopted, adapted to and in some cases resisted the use of electric underfloor heating. It concluded that attempts at promoting demand reduction by the electricity industry during the period 1945-1964 had only a limited effect on the trend towards rising energy end-use demand. This was, in part, due to the EDA's promotional efforts and conflicting objectives.

The recent review of historical energy studies by Pearson (2018) noted several problem areas, including the distinction between the many kinds of 'minor' and 'major' (or 'grand') transitions. He observed that the ability of historians to draw such distinctions with confidence has implications for their and our - capacity to comprehend the scale, pace, duration, smoothness and (dis)continuity or other 'special' properties of particular transitions. Such comprehension is however limited, as is its ability to offer insights into how to guide or manage them. Pearson (2018) argued, nevertheless, that historical analyses can offer insights into past energy transitions that are of value to non-historians who study past, current and prospective energy transitions and, where appropriate, to policymakers who seek to grapple with them. He also noted the ambiguity, even contradiction in the literature, and suggested that greater clarity would be valuable (Pearson, 2018). Finally, he extended an invitation to interested historians to further share the methods, subtleties and findings of historical analysis with non-historians, to enhance our knowledge, understanding and thinking about energy transitions. 


\section{Transition pathways}

\subsection{Visions of low-emissions, more-electric UK futures}

Several studies have been undertaken in recent years that yield low- or zero-emissions energy scenario sets for the UK (see, for example, the three UK pathway/scenario sets discussed by Allen and Hammond (2019)). The focus of this study is on the three pathways developed by the Transition Pathways Consortium (see Section 1.3). It consisted of UK engineers, social scientists, policy analysts and innovation specialists (and included the present authors). As noted, this consortium sought to develop and explore 'transition pathways' towards a UK low-carbon electricity system (Chilvers et al., 2017; Foxon et al., 2010), to understand the changing roles of large and small actors in the dynamics of these transitions, and to learn from the successes and failures of past transitions. The research team have focused on the choices and actions needed to 'get there from here', and on the analysis of technical, socioeconomic and environmental implications of the pathways (Chilvers et al., 2017; Foxon, 2013; Foxon et al., 2010; Hammond and O'Grady, 2014; Hammond et al., 2013; Hammond et al., 2019). An innovative, arguably robust, and 'whole systems' evidence base was developed that is distinctive from those devised elsewhere in the UK energy research community in its focus on governance 'logics' and structures. The pathways are not predictions or roadmaps; rather they are a way of imaginatively exploring future possibilities, including different approaches to governance, to inform proactive and protective decision making and enhance the potential for building consensus towards common goals (Chilvers et al., 2017; Hammond and Pearson, 2017).

An initial set of transition pathways for a UK low-carbon energy system was developed by applying three main steps (Foxon et al., 2010): (a) characterising the existing energy regime, its internal tensions and landscape pressures on it; (b) identifying dynamic processes at the niche level (see again Figure 2 (Foxon et al., 2010)); and (c) specifying interactions giving rise to, or strongly influencing, the transition pathways and potential branching points on them. They were devised by way of stakeholder workshops (involving UK energy researchers, industrialists, policy advisers and decision makers), a narrative descriptive of each pathway, and their subsequent technical elaboration (Barton et al., 2018). The stakeholder workshops were employed by the consortium to distinguish the 'governance logics' of three core sets of actors: driven by the market, central government intervention and local community initiatives. Consequently, the three transition pathways were, respectively, named MR, CC and TF; each being dominated by a single group's logic (Barton et al., 2018; Chilvers et al., 2017; Foxon et al., 2010; Hammond and Pearson, 2013, 2017). Chilvers et al. (2017) and Barton et al. (2018) summarise the development and high-level analysis of the v2.1 transition pathways set, to explain their key features and the distinctiveness and value of the approach, which builds inter alia on approaches originally devised by Dutch researchers (e.g. Geels, 2002; Rip and Kemp, 1998; Verbong and Geels, 2007). Thus, the consortium applied the MLP for analysing socio-technical transitions, based on interactions at and between the three levels noted earlier: niche innovations, sociotechnical regimes and macro-landscape pressures (see again Figure 2).

The development of the UK transition pathways has undergone several iterative loops. Earlier energy analysis and environmental LCA by Hammond et al. (2013) related to v1.1 of the pathways. However, a second iteration of these pathways was performed to investigate the limitations of that version in terms of technical feasibility, electric grid enhancement needs, social acceptability, energy and environmental performance, and also in the light of the outcomes of the stakeholder workshops (Chilvers et al., 2017; Foxon et al., 2010). Based on the logics of each of the three pathways, using a bottom-up approach, the change of energy use was determined, and the demand by sector was modelled (Barton et al., 2013). The progression of the electricity mix required to meet the demand, while adhering to the logic of each given pathway, was then projected (Barnacle et al., 2013). v2.1 enabled the pathways to be updated to incorporate further stakeholder inputs and developments in UK energy policy, as well as inputs from additional modelling. This updating also facilitated a revised life-cycle energy and carbon accounting of the pathways (Hammond and O'Grady, 2014, 2017a, 2017b) with an emphasis on the consequences of upstream emissions from power plants. Subsequently, other environmental and resource burdens of the v2.1 transition pathways were evaluated using the environmental or 'ecological' footprint technique (Hammond et al., 2019).

\subsection{Demand and supply portfolios for UK transition pathways}

An iterative approach was used to provide quantification of the demand and supply profiles for the UK transition pathways to 2050, by iterating between the narrative storylines and exploration of the pathways with a range of modelling and analysis tools (Barton et al., 2018; Chilvers et al., 2017). Key characteristics of the three transition pathways are summarised in Table 1 (Chilvers et al., 2017; Foxon, 2013). The starting point for the quantification of version 2.1 of these pathways was the projection of annual electricity demand by sector from 2010 to 2050 (Barton et al., 2013, 2018). In the MR pathway, the annual electricity demand rises from 337 terawatt hours (TWh) in 2010 to about 512 TWh in 2050 (see again Table 1), due to increasing use of electricity for industry, commercial, transport and domestic space heating and hot water. 
In contrast, annual electricity demand under the $\mathrm{CC}$ pathway rises from $337 \mathrm{TWh}$ in 2010 to some $410 \mathrm{TWh}$ in 2050 (Table 1). This pathway sees electricity demand rising and then levelling off from 2030 onwards, due to increasing use of electricity for transport and domestic space heating and hot water. However, it suggests higher rates of energy efficiency improvements in the domestic sector, and a smaller, highly efficient industrial sector with lower levels of output (Barton et al., 2013; Chilvers et al., 2017). This would imply that some energy-intensive UK production has moved to other countries, increasing the national consumption of goods produced abroad, implying that UK carbon dioxide emissions calculated on a consumption basis would continue to diverge from those on a production basis. Finally, under the TF pathway (Barton et al., 2013, 2018), the annual electricity demand falls from $337 \mathrm{TWh}$ in 2010 to only around $310 \mathrm{TWh}$ in 2050 (Table 1). Despite similar levels of electrification of transport to that in the other pathways, electricity demand falls due to even higher rates of energy efficiency improvements in the domestic and commercial sectors. Again, a small, highly efficient industrial sector with low levels of output aids the reduction in electricity demand. In all pathways a significant amount of energy is used in industry and commerce for space heating and water heating. The provision of this heat is mostly by way of the same technologies as in the domestic sector of each pathway, but often on a larger scale. Thus, in the MR and CC pathways, an increasing amount of electricity is used in heat pumps in the industrial and commercial sectors (Barton et al., 2018; Chilvers et al., 2017). This increase in demand for electricity for heating and hot water is additional to that required for electrification of transport, and it leads to a significant rise in total final electricity demand in these pathways. However, under the TF pathway, the total final electricity demand remains stable up to 2050 , as the increase in transport electricity consumption is offset by reductions in demand as a result of energy efficiency improvements. Thus, there is no rise in electricity demand for heating and hot water under the TF pathway, mainly due to the expansion of community-scale renewable combined heat and power (CHP).

The energy demand requirements under v2.1 of all the pathways (Barton et al., 2018) are met by rising levels of lowcarbon electricity generation, including different generation capacities of renewables, nuclear power and fossil fuels (e.g. coal and, in the future, mainly gas) with CCS, operating at different capacity factors. The detailed generation capacity schedule for each pathway from 2010 to 2050 is reported by Barnacle et al. (2013) and Barton et al. (2013): see Figures 3-5 (corresponding demand projections were presented graphically by Barton et al. (2018)). In 2010, the UK had around 95 gigawatts (GW) of electricity generation capacity, including $29 \mathrm{GW}$ of coal and dual-fuel generation, $33 \mathrm{GW}$ of gas-fired generation, $11 \mathrm{GW}$ of nuclear power, $9 \mathrm{GW}$ of renewable generation and $6 \mathrm{GW}$ of CHP cogeneration (Barnacle et al., 2013; Barton et al., 2013). Significant amounts of capacity are then required to come on stream under the MR pathway in the 2020s (Barton et al., 2018; Chilvers et al., 2017): see Figure 3. Subsequently, $21 \mathrm{GW}$ of fossil-fuelled generation with CCS, $15 \mathrm{GW}$ of nuclear power and $47 \mathrm{GW}$ of renewables are needed by 2030; giving a total capacity of around $130 \mathrm{GW}$ by 2030

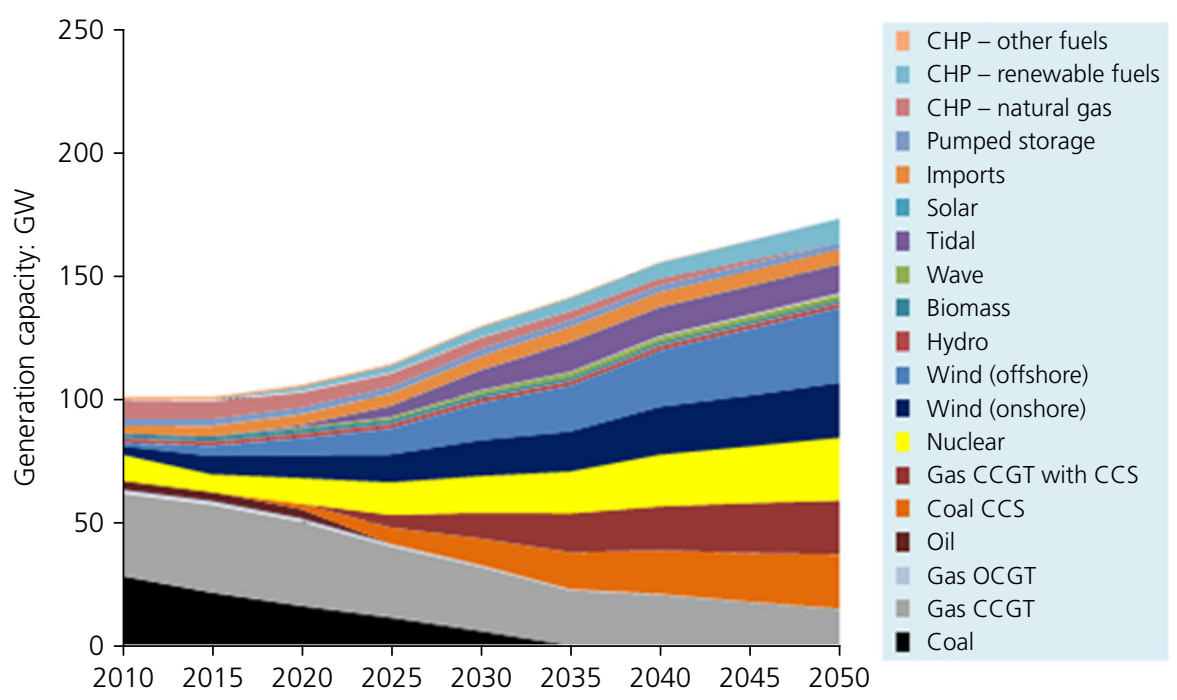

Figure 3. Generation capacity in the MR pathway for the UK (source: Barton et al. (2018); updated from Barnacle et al. (2013)). CCGT, combined cycle gas turbine; OCGT, open cycle gas turbine. A full-colour version of this figure can be found on the ICE Virtual Library (www.icevirtuallibrary.com) 


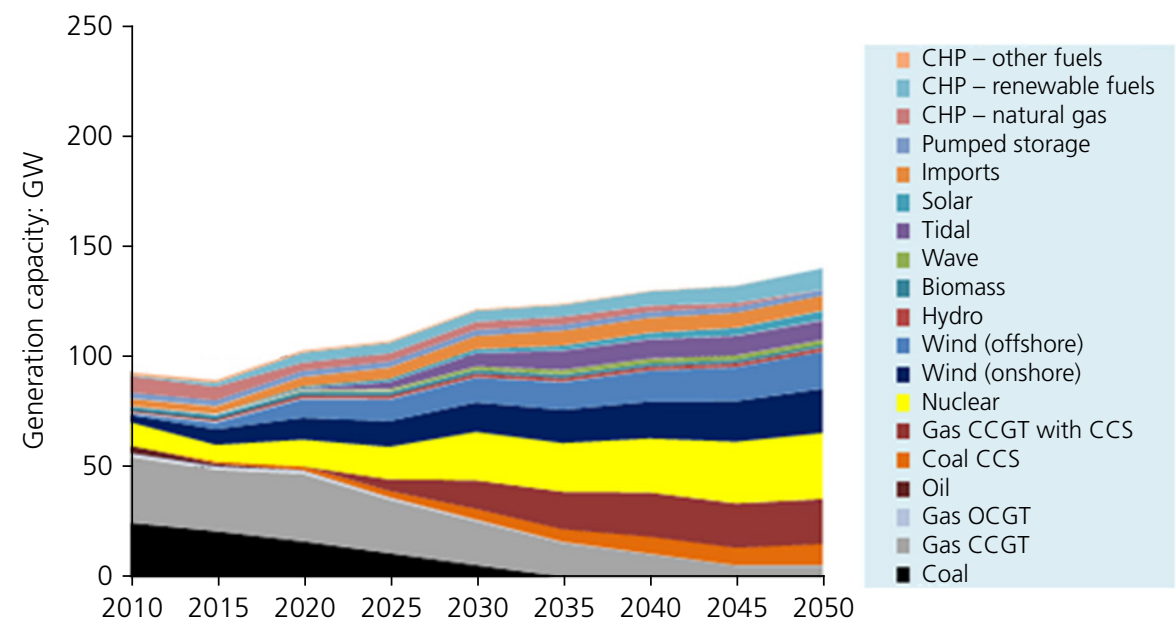

Figure 4. Generation capacity in the CC pathway for the UK (source: Barton et al. (2018); updated from Barnacle et al. (2013)). A full-colour version of this figure can be found on the ICE Virtual Library (www.icevirtuallibrary.com)

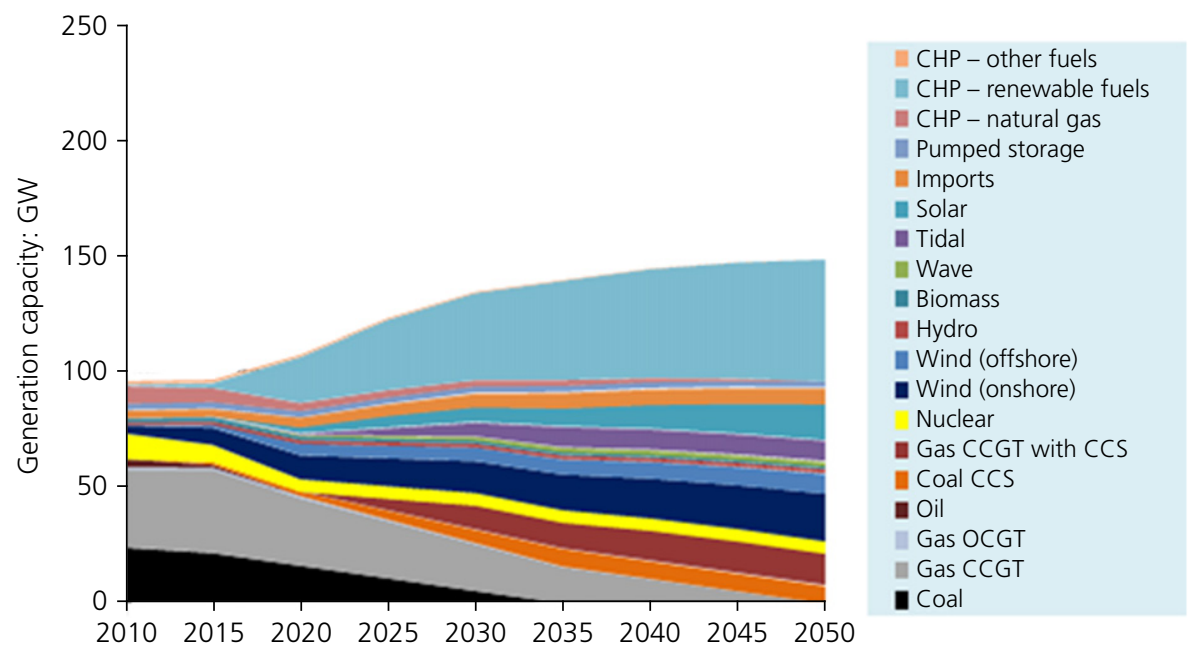

Figure 5. Generation capacity in the TF pathway for the UK (source: Barton et al. (2018); updated from Barnacle et al. (2013)). A full-colour version of this figure can be found on the ICE Virtual Library (www.icevirtuallibrary.com)

(Barnacle et al., 2013; Barton et al., 2013). This deployment leads to further increases in capacity to meet rising electricity demand over following decades, particularly from industry and electrification of heating and transport (Barton et al., 2018; Chilvers et al., 2017). Thus, a total of some $168 \mathrm{GW}$ of capacity is installed by 2050 , including $44 \mathrm{GW}$ of fossil-fuelled generation with CCS, $26 \mathrm{GW}$ of nuclear power and $80 \mathrm{GW}$ of renewable capacity, principally from onshore $(23 \mathrm{GW})$ and offshore $(30 \mathrm{GW})$ wind turbines, tidal power $(12 \mathrm{GW})$ and renewable CHP ( 9 GW).
Similar investments occur in all types of low-carbon generation capacity under the CC pathway during the 2020s (Barton et al., 2018; Chilvers et al., 2017): see Figure 4; perhaps coordinated by a strategic energy agency. This could lead to a total of some $122 \mathrm{GW}$ in 2030 (Barnacle et al., 2013; Barton et al., 2013), including high levels of nuclear power (22 GW), slightly lower levels of fossil-fuelled power generation with CCS $(18 \mathrm{GW})$, and less renewables $(43 \mathrm{GW})$. Electricity demand levels off under this pathway, but further power plant deployment would be required to increase the capacity to 
about $151 \mathrm{GW}$ in total by 2050 (Barton et al., 2018; Chilvers et al., 2017). The main contributions are likely to come from nuclear power $(30 \mathrm{GW})$ and fossil-fuelled power generation with CCS $(30 \mathrm{GW})$, although the latter operates at a lower capacity factor $(36 \%)$, because it again partly provides a back-up for intermittent renewables $(65 \mathrm{GW})$. Finally, action by community groups, as well as local and regional ESCos, under the TF pathway, result in a significant expansion of community-based and micro-scale renewable CHP installed from 2020 onwards (Barton et al., 2018; Chilvers et al., 2017). This reaches a total capacity of $37 \mathrm{GW}$ by 2030 and about 149 GW by 2050 (Barnacle et al., 2013; Barton et al., 2013): see Figure 5. This is at a similar level to that under the CC pathway, although most plant is made up of renewable generation $(112 \mathrm{GW})$. A significant proportion of demand under the TF pathway is met by local-scale renewables (Barton et al., 2018; Chilvers et al., 2017): from renewable (biogas) community-scale and micro-CHP systems $(44 \mathrm{GW})$, followed by onshore wind turbines $(21 \mathrm{GW})$, solar PV arrays $(16 \mathrm{GW})$ and offshore wind farms $(8 \mathrm{GW})$. There are also likely to be some low-carbon investments in earlier periods, possibly leading to $22 \mathrm{GW}$ of fossil-fuelled power plant with CCS and $5 \mathrm{GW}$ of nuclear capacity by 2050 .

\section{Concluding remarks}

A large interdisciplinary consortium of engineers, social scientists and policy analysts has developed three low-carbon, more-electric transition pathways for the UK: described as MR, CC and TF, respectively. The study builds on an approach based on earlier work on understanding transitions, using an MLP with landscape, regime and niche levels, and its application to the development of 'socio-technical scenarios'. These pathways to 2050 focus on the power sector, including the potential for increasing use of low-carbon electricity for heating and transport. Here (in part 1), studies of historical energy and infrastructure transitions have helped understand the dynamics and timing of past transitions, as well as the contexts and conditions that influenced them. Pearson (2018) recently argued that historical analyses offer insights into past energy transitions that are of value to non-historians who study past, current and prospective energy transitions and, where appropriate, to policymakers who seek to grapple with them.

The extent to which choices need to be made by UK energy policy makers and stakeholders between the large-scale and small-scale actors, pathways and associated technologies are discussed (Foxon, 2013; Hammond and Pearson, 2017). Here (in part 1 of this two-part contribution), the present UK transition pathways are used to highlight the fact that significantly different technological pathways to a low-carbon electricity system in the UK by 2050 are possible, although any of these pathways will be challenging to realise. They imply differing levels of effort and different patterns of risks and uncertainties and approaches to the system's governance. Each exhibits challenges in relation to energy efficiency and behavioural changes, as well as technology choices and their rate of deployment (Barton et al., 2018). The way in which these are addressed and resolved will depend on the governance arrangements of the low-carbon transition, including policy measures and regulatory frameworks. So, the roles and choices of market, government and civil society actors are crucial to realising any of these pathways (Chilvers et al., 2017). In part 2, horizon scanning and energy technology assessments (ETAs) of the energy technologies that influence the three UK transition pathways are employed to provide an understanding of the future interplay of the energy policy trilemma - that is, achieving deep GHG emission cuts, while maintaining a secure and affordable energy system - and addressing how resulting tensions might be resolved. Indicative ETAs are used to identify the components of a balance sheet of technological credits and debits to evaluate their societal impacts, and to determine whether they are compatible with Britain's move towards a low-carbon future in 2050 and beyond. All three pathways (MR, CC and TF) are evaluated in terms of their environmental performance using complementary LCA and footprinting methods. The energy analysis and environmental LCAs reported by Hammond et al. (2013) and Hammond and O'Grady $(2014,2017 \mathrm{a}, 2017 \mathrm{~b})$, evaluated $\mathrm{v} 1 \cdot 1$ and $\mathrm{v} 2.1$ of the pathways, respectively. EFA are also employed to estimate the environmental and resource burdens associated with UK power generation based on historic data and the three transition pathways (Hammond et al., 2019). The so-called 'disruptive' technological options are examined to provide recommendations on the framing of future energy policy choices that limit the environmental consequences of future electricity systems. It is argued that the value of any new policy direction must be evaluated not only against mediumterm climate change (or GHG emission) goals, but against long-term, system-wide goals over a wider spectrum of environmental metrics.

\section{Acknowledgements}

The authors led a large consortium of nine university partners funded through the strategic partnership between E.on UK (the electricity generator) and the UK EPSRC to study the role of electricity within the context of 'Transition Pathways to a Low Carbon Economy' (under grant EP/F022832/1). It was subsequently renewed with funding solely from the EPSRC under the title 'Realising Transition Pathways: Whole Systems Analysis for a UK More Electric Low Carbon Energy Future' (grant reference EP/K005316/1). All the authors are grateful for the interaction with other members of these research consortia and colleagues within E.on Engineering. However, the 
views expressed in this paper are those of the authors alone, and do not necessarily reflect the policies of the funders or other partners. The authors' names are listed alphabetically.

\section{REFERENCES}

Allen RC (2009) The British Industrial Revolution in Global Perspective. Cambridge University Press, Cambridge, UK.

Allen PE and Hammond GP (2019) Bioenergy utilisation for a low carbon future in the UK: the evaluation of some alternative scenarios and projections. BMC Energy 1: article 3.

Arapostathis S, Pearson PJG and Foxon TJ (2014) UK Natural gas system integration in the making, 1960-2010: complexity, transitional uncertainties and uncertain transitions. Environmental Innovation and Societal Transitions 11: 87-102.

Arapostathis S, Laczay S and Pearson PJG (2019) Steering the 'C-Day': insights from the rapid, planned transition of the UK's natural gas conversion programme. Environmental Innovation and Societal Transitions 32: 122-139.

Ares E and Hirst D (2015) Paris Climate Change Conference. House of Commons Library, London, UK, Briefing Paper CPB 7393.

Barnacle M, Robertson E, Galloway S, Barton J and Ault G (2013) Modelling generation and infrastructure requirements for transition pathways. Energy Policy 52: 60-76.

Barton J, Huang S, Infield D et al. (2013) The evolution of electricity demand and the role for demand side participation, in buildings and transport. Energy Policy 52: 85-102.

Barton J, Davies L, Dooley B et al. (2018) Transition pathways for a UK low carbon electricity system: comparing scenarios and technology implications. Renewable and Sustainable Energy Reviews 82(3): 2779-2790.

BEIS (Department for Business, Energy \& Industrial Strategy) (2019) Digest of United Kingdom Energy Statistics 2019. The Stationery Office Limited, London, UK.

Busch J, Foxon TJ and Taylor P (2018) Designing industrial strategy for a low carbon transformation. Environmental Innovation and Societal Transitions 29: 114-125.

Carlsson-Hyslop A (2016) Past management of energy demand: promotion and adoption of electric heating in Britain 1945-1964 Environment and History 22(1): 75-102.

CCC (Committee on Climate Change) (2015) The Fifth Carbon Budget The Next Step Towards a Low-Carbon Economy. CCC, London, UK.

CCC (2019) Net Zero - The UK's Contribution to Stopping Global Warming. CCC, London, UK.

Chilvers J, Foxon TJ, Galloway S et al. (2017) Realising transition pathways for a more electric, low carbon energy system in the UK: challenges, insights and opportunities. Proceedings of the Institution of Mechanical Engineers Part A: Journal of Power and Energy 231(6): 440-477.

Climate Change Act 2008. Chapter 27. Her Majesty's Stationery Office, London, UK.

Cooper SJG and Hammond GP (2018) 'Decarbonising' UK industry: towards a cleaner economy. Proceedings of the Institution of Civil Engineers - Energy 171(4): 147-157, https://doi.org/10.1680/ jener.18.00007.

de Bruijn H and Herder PM (2009) System and actor perspectives on sociotechnical systems. IEEE Transactions on Systems, Man, and Cybernetics - Part A: Systems and Humans 39(5): 981-992.

DECC (Department of Energy and Climate Change) (2011) The Carbon Plan: Delivering Our Low Carbon Future. DECC, London, UK.
Elzen B, Geels FW and Green K (eds) (2004) System Innovation and the Transition to Sustainability - Theory, Evidence and Policy. Edward Elgar, Cheltenham, UK.

Foxon TJ (2013) Transition pathways for a UK low carbon electricity future. Energy Policy 52: 10-24.

Foxon TJ, Hammond GP and Pearson PJ (2010) Developing transition pathways for a low carbon electricity system in the UK. Technological Forecasting and Social Change 77(8): 1203-1213.

Geels F (2002) Technological transitions as evolutionary reconfiguration processes: a multilevel perspective and a case study. Research Policy 31(8-9): 1257-1274.

Geels F (2005) Technological Transitions and System Innovations: A Co-Evolutionary and Socio-Technical Analysis. Edward Elgar, Cheltenham, UK

Geels FW (2006) The hygienic transition from cesspools to sewer systems (1840-1930): the dynamics of regime transformation. Research Policy 35(7): 1069-1082.

Geels FW (2010) Ontologies, socio-technical transitions (to sustainability), and the multi-level perspective. Research Policy 39(4): 495-510.

Geels FW (2011) The multi-level perspective on sustainability transitions: responses to seven criticisms. Environmental Innovation and Societal Transitions 1(1): $24-40$.

Geels FW (2019) Socio-technical transitions to sustainability: a review of criticisms and elaborations of the Multi-Level Perspective. Current Opinion in Environmental Sustainability 39: 187-201.

Geels FW and Raven RPJM (2006) Non-linearity and expectations in niche development trajectories: ups and downs in Dutch biogas development (1973-2003). Technology Analysis \& Strategic Management 18(3-4): 375-392.

Geels FW and Schot J (2007) Typology of sociotechnical transition pathways. Research Policy 36(3): 399-417.

Geels FW, Kern F, Fuchs G et al. (2016) The enactment of socio-technical transition pathways: a reformulated typology and a comparative multi-level analysis of the German and UK low-carbon electricity transitions (1990-2014). Research Policy 45(4): 896-913.

Grubler A (2012) Energy transitions research: insights and cautionary tales. Energy Policy 50: 8-16.

Hammond GP (2000) Energy, environment and sustainable development: a UK perspective. Transactions of the Institution of Chemical Engineers Part B: Process Safety and Environmental Protection 78(4): 304-323.

Hammond GP and O'Grady Á (2014) The implications of upstream emissions from the power sector. Proceedings of the Institution of Civil Engineers - Energy 167(1): 9-19, https://doi.org/10.1680/ ener.13.00006.

Hammond GP and Pearson PJ (2013) Challenges of the transition to a low carbon, more electric future: from here to 2050. Energy Policy 52: $1-9$.

Hammond GP and Pearson PJG (2017) Realising transition pathways to a low-carbon future (Editorial). Proceedings of the Institution of Mechanical Engineers Part A: Journal of Power and Energy 231(6): 435-439.

Hammond GP, Howard HR and Jones Cl (2013) The energy and environmental implications of more electric UK transition pathways: a whole systems perspective. Energy Policy 52: $103-116$.

Hammond GP, Howard HR and Singh Rana H (2019) Environmental and resource burdens associated with low carbon, more electric transition pathways to 2050: footprint components from carbon emissions and land use to waste arisings and water consumption. Global Transitions 1: 28-43. 
HMG (HM Government) (2017) The Clean Growth Strategy: Leading the Way to Low Carbon Future. Department of Business, Energy and Industrial Strategy (BEIS), London, UK.

HMG (2019) The Climate Change Act 2008 (2050 Target Amendment) Order 2019. The Stationery Office, London, UK, Statutory Instrument 2019 No. 1056.

IPCC (Intergovernmental Panel on Climate Change) (2013) Climate Change 2013 - The Physical Science Basis. World Meteorological Office (WMO)/United Nations Environment Programme (UNEP), Geneva, Switzerland

IPCC (2019) Global Warming of $1.5^{\circ} \mathrm{C}$ - Summary for Policymakers. IPCC, Geneva, Switzerland, Report SR15-SPM.

Johnson VCA, Sherry-Brennan F and Pearson PJG (2016) Alternative liquid fuels in the UK in the inter-war period (1918-1938): insights from a failed energy transition. Environmental Innovation and Societal Transitions 20: 33-47.

Kemp R (1994) Technology and the transition to environmental sustainability: the problem of technological regime shifts. Futures 26(10): 1023-1046.

Kemp R and Rotmans J (2005) The management of the co-evolution of technical, environmental and social systems. In Towards Environmental Innovation Systems (Weber M and Hemmelskamp J (eds)). Springer-Verlag, Berlin, Germany, ch. 8, pp. 33-55.

Kemp R and van Lente H (2011) The dual challenge of sustainability transitions. Environmental Innovation and Societal Transitions 1(1) 121-124.

Kemp R, Rotmans J and Loorbach D (2007) Assessing the Dutch energy transition policy: how does it deal with dilemmas of managing transitions? Journal of Environmental Policy \& Planning 9(3-4): 315-331.

Kern F and Smith A (2008) Restructuring energy systems for sustainability? Energy transition policy in the Netherlands. Energy Policy 36(11): 4093-4103.

Kohler J, Geels FW, Kern F et al. (2019) An agenda for sustainability transitions research: state of the art and future directions. Environmental Innovation and Societal Transitions 31: 1-32.

Kwakkel JH and Yücel G (2014) An exploratory analysis of the Dutch electricity system in transition. Journal of the Knowledge Economy 5(4): 670-685.

Laes E, Gorissen L and Nevens F (2014) A comparison of energy transition governance in Germany, the Netherlands and the United Kingdom. Sustainability 6(3): 1129-1152.

Loorbach D (2007) Transition Management: New Mode of Governance for Sustainable Development. International Books, Utrecht, the Netherlands.

Loorbach D, Frantzeskaki N and Huffenreuter RL (2015) Transition management: taking stock from governance experimentation. The Journal of Corporate Citizenship 58(58): 48-66.

Markard J, Raven R and Truffer B (2012) Sustainability transitions: an emerging field of research and its prospects. Research Policy 41(6) 955-967.

MEA (Ministry of Economic Affairs) (2005) Now for Later - Energy Report 2005. MEA, The Hague, the Netherlands.

Meadowcroft J (2009) What about the politics? Sustainable development, transition management, and long term energy transitions. Policy Sciences 42: 323-340.

Pearson PJG (2018) Past, present and prospective energy transitions: an invitation to historians. Journal of Energy History/Revue d'Histoire de l'Énergie 1: article 4. See https://energyhistory.eu/fr/ dossier/past-present-and-prospective-energy-transitions-invitationhistorians (accessed 26/02/2020).

Pearson PJG and Arapostathis S (2017) Two centuries of innovation, transformation and transition in the UK gas industry: where next?
Proceedings of the Institution of Mechanical Engineers Part A: Journal of Power and Energy 231(6), 478-497.

Rip A and Kemp R (1998) Technological change. In Human Choices and Climate Change (Rayner S and Malone EL (eds)). Battelle Press, Columbus, OH, USA, vol. 2, ch. 6, pp. 70-73.

Rotmans J and Kemp R (2008) Detour ahead: a response to Shove and Walker about the perilous road of transition management. Environment and Planning A 40(4): 1006-1012.

Shackley S and Green K (2005) A conceptual framework for exploring transitions to decarbonised energy systems in the UK. Energy 32(3): 221-236.

Shove E and Walker G (2007) CAUTION! Transitions ahead: politics, practice, and sustainable transition management. Environment and Planning A 39(4): 763-770.

Smil V (2017) Energy and Civilisation: A History. MIT Press, Cambridge, MA, USA.

Smith A (2009) Energy governance: the challenges of sustainability. In Energy for the Future: A New Agenda (Scrase I and MacKerron G (eds)). Palgrave Macmillan, Basingstoke, UK, ch. 4, pp. 35-75.

Smith A, Voß JP and Grin J (2010) Innovation studies and sustainability transitions: the allure of the multi-level perspective and its challenges. Research Policy 39(4): 435-448.

Sovacool BK and Geels FW (2016) Further reflections on the temporality of energy transitions: a response to critics. Energy Research \& Social Science 22: 232-237.

Spencer T, Pierfederici R, Sartor O et al. (2017) Tracking sectoral progress in the deep decarbonisation of energy systems in Europe. Energy Policy 110: 509-517.

Verbong G and Geels F (2007) The ongoing energy transition: lessons from a socio-technical, multi-level analysis of the Dutch electricity system (1960-2004). Energy Policy 35(2): 1025-1037.

Verbong GP and Geels FW (2010) Exploring sustainability transitions in the electricity sector with socio-technical pathways. Technological Forecasting and Social Change 77(8): 1214-1221.

Voß JP, Smith A and Grin J (2009) Designing long-term policy: rethinking transition management. Policy Sciences 42(4): 275-302.

Wilson C and Grubler A (2011) Lessons from the history of technological change for clean energy scenarios and policies. Natural Resources Forum 35(3): 165-184.

WMO (World Meteorological Office) (2019) Greenhouse Gas Bulletin, No. 15. WMO, Geneva, Switzerland.

Wrigley EA (2010) Energy and the English Industrial Revolution. Cambridge University Press, Cambridge, UK.

\section{How can you contribute?}

To discuss this paper, please email up to 500 words to the editor at journals@ice.org.uk. Your contribution will be forwarded to the author(s) for a reply and, if considered appropriate by the editorial board, it will be published as discussion in a future issue of the journal.

Proceedings journals rely entirely on contributions from the civil engineering profession (and allied disciplines). Information about how to submit your paper online is available at www.icevirtuallibrary.com/page/authors, where you will also find detailed author guidelines. 